\title{
Effect of Micro- and Nano-Sized Carbonous Solid Lubricants as Oil Additives in Nanofluid on Tribological Properties
}

\author{
Emad Omrani ${ }^{1,2, *(D)}$, Pradeep L. Menezes ${ }^{2}\left(\mathbb{D}\right.$ and Pradeep K. Rohatgi ${ }^{1}$ \\ 1 Department of Materials Science and Engineering, College of Engineering \& Applied Science, \\ University of Wisconsin-Milwaukee, Milwaukee, WI 53211, USA; prohatgi@uwm.edu \\ 2 Department of Mechanical Engineering, University of Nevada-Reno, Reno, NV 89557, USA; \\ pmenezes@unr.edu \\ * Correspondence: eomrani@unr.edu or emad.omrani@gmail.com
}

Received: 28 January 2019; Accepted: 7 March 2019; Published: 15 March 2019

\begin{abstract}
The tribological behavior of graphene and graphite as additives in canola oil was investigated with a pin-on-disk tribometer. The wear surfaces of the aluminum pins lubricated with the additive-containing canola oil were analyzed by scanning electron microscopy (SEM). It was found that graphene and graphite as additives in oil show a lower coefficient of friction and wear rate in comparison with neat canola oil. The graphene sheets are more effective than graphite flakes to reduce friction and wear. In addition, there is a proper concentration where the coefficient of friction (COF) and wear are in minimum value. The optimal concentration of the additive in canola oil is about $0.7 \mathrm{wt} \%$. Therefore, the load-carrying capacity and antiwear ability of the lubricating oil are improved. Moreover, the worn surface of aluminum pins is smother in the presence of solid lubricant rather than neat oil.
\end{abstract}

Keywords: graphene; graphite; oil additives; tribology; wear

\section{Introduction}

Friction and wear are important issues for energy and materials loss in industry. To improve energy efficiency and mechanical durability, the conventional solution is lubricants to reduce friction and wear. Regardless of the surface finishing of materials, the surfaces contain ridges, valleys, asperities and depressions [1]. One of the major topics to be investigated in this field is improving performance of lubricants and chemical additives to enhance the effective operation of components or two surfaces in contact, and to ensure the lubricants are able to reach and maintain the desired mechanical efficiencies.

It is well-known that additives can improve the lubrication performance of lubricants. Quite recently, considerable attention has been paid to nanoparticles as additives in a base oil for tribology applications [2-4]. Current research on oil additives is focused on synthesis and preparation of nanoparticles and investigating the role of nanoparticles in tribological properties and the lubrication mechanism. The previous studies confirmed the findings of improving the extreme-pressure property and load-carrying capacity with the presence of nanoparticles in base oil. Thus, a significant reduction in the coefficient of friction and wear loss will be observed. Popular explanations of mechanisms of nanoparticle additives include (1) ball effect [5,6] (2) tribochemical reactions [7,8]; and (3) adsorption film theory [9]. Using nanoparticles as an additive for lubricants is a rapidly progressing field of research because nanoparticles have superior properties in comparison with other materials due to their extremely small size and high specific surface area [10-12].

There are several types of additives that can be categorized into two major types based on the materials' nature, hard ceramic particles and solid lubricants [13]. Amongst nanoparticles, the 
solid lubricants such as molybdenum disulfide $\left(\mathrm{MoS}_{2}\right)$ [14] and nano graphite [15,16] dispersed in oil exhibited beneficial effects by reducing the friction and wear. Graphite and graphene were used to enhance the tribological properties of materials as reinforcement [17-19] or as oil additive $[20,21]$. It is reported a layer of solid lubricant continuously forms on the tribo-surface, during dry sliding of the metal-graphite composites [22-24]. A composite reinforced with graphite particles at proper concentration has better tribological properties because graphite particles act as a solid lubricant on worn surfaces [25-27], leading to graphite particles as an additive in oil [15,20,28,29]. Lee et al. [15] separated graphite nanoparticles into industrial gear oil, and the results indicated graphite nanoparticles can improve the lubrication properties significantly. Huang et al. [20] used graphite nanosheets as an additive in paraffin oil to analyze the tribological behavior with a four-ball and pin-on-disk friction and wear tester. They proved that the graphite nanosheets as an additive in oil at proper concentration can improve tribological properties, load-carrying capacity, and antiwear ability, so as to decrease the friction coefficient. Aranganathan et al. [28] compared the effect of natural graphite (NG) and thermo-graphite (TG) contained in Non-Asbestos Organic (NAO) friction materials (FMs). The tribo-performance of TG-based FMs proved superior to NG-based ones excluding recovery performance.

Graphene platelets (GNPs) [29] are the fascinating fundamental component of graphite, and the excellent lubricative properties of graphite have been examined. When the thickness of GNPs increases in several layers, the frictional force between an Atomic Force Microscopy (AFM) tip and graphene decreases and is independent of a substrate [30]. A very low friction coefficient and high-pressure resistance of graphene make it be a prospective reinforcement for lubricant and antiwear coatings [31-34]. Recently, GNPs as additives in base lubricants became a hot research subject. Eswaraiah et al. [21] manufactured Ultrathin graphene-based engine oil nanofluids, and observed reduction in frictional coefficient. They also found the frictional characteristics and wear scar diameter increases with the increase in the concentration of graphene. Arwin and Rashmi [35] determined using GNPs as an additive for two different biolubricant base stocks resulted in the reduction of the coefficient of friction and a negative effect at a higher temperature. Some experiments showed the modification of GNPs can improve the dispersion of graphene platelets in base oil, the wear resistance and load-carrying capacity of the machine, while reducing the resistance to shear and wear scar diameter $[16,36,37]$.

In the present work, the graphite and graphene were mixed with canola oil, and the tribological properties of the graphite and graphene as a lubricating additive in canola oil were investigated.

\section{Experimental Works}

The test specimen for the tribological experiments was aluminum 2024 which is commonly employed in tribological applications (for example, in motor engines and pistons). The aluminum 2024 hardness, as determined with a Vickers, was $142 \pm 3$. Aluminum cylindrical sliders $(6 \mathrm{~mm}$ diameter with hemispherical tip) with a flat aluminum disk counterface ( $55 \mathrm{~mm}$ diameter and $10 \mathrm{~mm}$ thickness) were prepared to assess the friction and wear properties using a control lubricant with a different type of carbon additives. The disk was abraded by 220 sandpaper and the initial surface roughness parameter $\left(\mathrm{S}_{\mathrm{a}}\right)$ of the disk was $14.26 \mu \mathrm{m}$. The lubricant selected for this study was a canola oil (also known as rapeseed oil) with a viscosity index of 126 . Due to good lubricity properties, canola oil is a popular lubricant for tribological investigations. It is required to study the beneficial effects of additives for canola oil under boundary conditions [38,39].

In the current investigation, commercially available graphite and graphene, Nano19 graphene nanoplatelets (GNPs) and 4506 Graphite (Asbury Carbons Inc., Asbury, NJ, USA) were selected as oil additives. The average thickness of graphene and graphite was approximately $10 \mathrm{~nm}$ and $25 \mu \mathrm{m}$ with an average platelet diameter of approximately $5 \mu \mathrm{m}$. All particles were added (in several additive weight fractions) to the canola oil and stirred with three different methods to find the optimum mixture methods. One of the important factors for oil and additive performance is to have a well-dispersed 
mixture such that its composition is considered homogenous and keep it well-dispersed during the tribology test. The three methods of mixing were (1) shaking for $20 \mathrm{~min}$ at room temperature, (2) using an ultrasonic mixer (UM) for $2 \mathrm{~h}$ at $60{ }^{\circ} \mathrm{C}$ [40], and (3) shaking and then using an ultrasonic mixer as explained in (1) and (2). The results exhibited that the mixture of oil-carbon prepared by ultrasonic mixture had more stability and will be discussed in a succeeding explanation. To ensure appropriate lubricant compositions, the tribological tests were conducted immediately after preparation of the oil mixtures. All sliding friction and wear experiments were conducted with pin-on-disk at room temperature. The pin was a hemispherical cap of radius of $3 \mathrm{~mm}$. The test conditions were as follows: $10 \mathrm{~N}$ applied load with a contact pressure of $700 \mathrm{MPa}$; sliding speed, $20 \mathrm{~mm} / \mathrm{s}$; and sliding distance, $1500 \mathrm{~m}$. These conditions resulted in a severe boundary condition. Investigating the lubrication regime for the following experiments is an important preliminary step when characterizing the friction mechanisms between the pin and the disk surfaces. This can be achieved by utilizing the elastohydrodynamic minimum film thickness equation developed by Hamrock and Dowson, which is applicable in many material combinations for a variety of contact geometries including point contact of a hemisphere on a flat surface and the geometry for the pin-on-disk testing. The numerically derived formula for the minimum film thickness is expressed in the following form:

$$
\frac{h_{0}}{R^{\prime}}=3.63\left(\frac{U \eta_{0}}{E^{\prime} R^{\prime}}\right)^{0.68}\left(\alpha E^{\prime}\right)^{0.49}\left(\frac{w}{E^{\prime} R^{\prime 2}}\right)^{-0.073}\left(1-e^{-0.68 k}\right)
$$

where $h_{0}$ is the minimum film thickness $(\mathrm{m})$; $U$ is the entraining surface velocity $(\mathrm{m} / \mathrm{s})$ (i.e., $U=$ $\frac{\left(U_{a}+U_{b}\right)}{2}$, where the subscripts ' $a$ ' and ' $b$ ' refer to the velocities of bodies ' $a$ ' and ' $b$ ' respectively); $\eta_{0}$ is the viscosity at atmospheric pressure of the lubricant (Pa s); $E^{\prime}$ is the reduced Young's modulus (Pa) (i.e., $\frac{1}{E^{\prime}}=\frac{1}{2}\left(\frac{1-v_{a}^{2}}{E_{a}}+\frac{1-v_{b}^{2}}{E_{B}}\right)$ where $v$ is Poisson's ratio and $E$ is Young's modulus for the respective pin and disk specimen); $R^{\prime}$ is the reduced radius of curvature $(\mathrm{m})$ for a pin on flat (i.e., $\frac{1}{R^{\prime}}=\left(\frac{1}{R_{a x}}+\frac{1}{R_{a y}}\right)$, where $R_{a}$ is the radius of curvature for the pin in the $x$ and $y$ directions); $A$ is the pressure-viscosity coefficient $\left(\mathrm{m}^{2} / \mathrm{N}\right)$ (i.e., $\left.\alpha=\left(0.6+0.965 \log _{10} \eta_{0}\right) \times 10^{-8}\right) ; w$ is the normal load $(\mathrm{N})$; and $k$ is the ellipticity parameter defined as $k=a / b$, where ' $a$ ' is the semiaxis of the contact ellipse in the transverse direction (m) and ' $b$ ' is the semiaxis in the direction of motion (m). However, in this calculation the value of the ellipticity parameter for point contact was $k=1$.

In the present experimental conditions, the pin tip radius was $3 \mathrm{~mm}$, the sliding speed was $20 \mathrm{~mm} / \mathrm{s}$, and the normal load was $10 \mathrm{~N}$. Hamrock and Dowson's elastohydrodynamic film thickness equation predicted a minimum film thickness ratio of $5.1 \times 10^{-6}$ or less. These values were significantly less than unity and place the current experimental investigation in the boundary lubrication regime. It can be inferred that for the variety of testing conditions presented in this experimental study, the lubricating regime will remain in the boundary lubrication. Each test lubricant was tested on the tribotester for a minimum of three trials to validate friction and wear performance of the test lubricant.

The worn surface was explored with a 3D optical microscope and an optical microscope. Additionally, Scanning Electron Microscope (SEM) and Energy-dispersive X-ray spectroscopy (EDX) (Hitachi S-4700, Tokyo, Japan) were employed to analyze the worn surfaces to understand the topographical features, the chemistry of worn surface and the underlying lubrication mechanisms after the tribological tests.

The coefficient of friction (COF) values are the average friction value for each test, averaged for the set of three trials. In addition, the vertical displacement of the pin was recorded by a linear variable differential transducer (LVDT) with an encoder. Therefore, the linear wear-loss was calculated, and can be converted to a volumetric wear loss $\left(V, \mathrm{~mm}^{3}\right)$ by using Equation (1) derived from the geometry of a spherical cap:

$$
V=\frac{\pi h^{2}}{3}(3 r-h)
$$


where $h$ is the vertical linear displacement ( $\mathrm{mm}$ ) for the pin and $r$ is the pin radius (mm), which is assumed to be constant.

During each of the tests the surface of the disk was partially submerged by the nanolubricant mixture, thereby continually lubricating the pin-disk interface throughout the duration of the test. The pin and disk specimens were cleaned before and after each test using an ultrasonic cleaner with hexane solutions.

\section{Results and Discussions}

\subsection{Dispersion Stability}

All three methods showed a good dispersion appearance of particles into the oil. Figure 1 illustrates the dispersion of $0.2 \mathrm{wt} \%$ graphene into the oil. Observations of the experiments revealed that after one day of mixing, the shaking then UM mixing method started settling the particles from the top while the two other methods were still well dispersed (Figure 1b). After five days, the settlement of particles was observed in the shaking method while the ultrasonic mixing methods were still homogenized (Figure 1c). After 13 days, most of the graphene particles had settled to the bottom of the containers for shaking and shaking then UM mixing methods even though graphene tended to settle at the container bottom for the ultrasonic mixing method (Figure 1d). Therefore, the ultrasonic mixing method for $2 \mathrm{~h}$ at $60^{\circ} \mathrm{C}$ was selected to use for mixing due to increased stability of dispersion of solid lubricant particles.
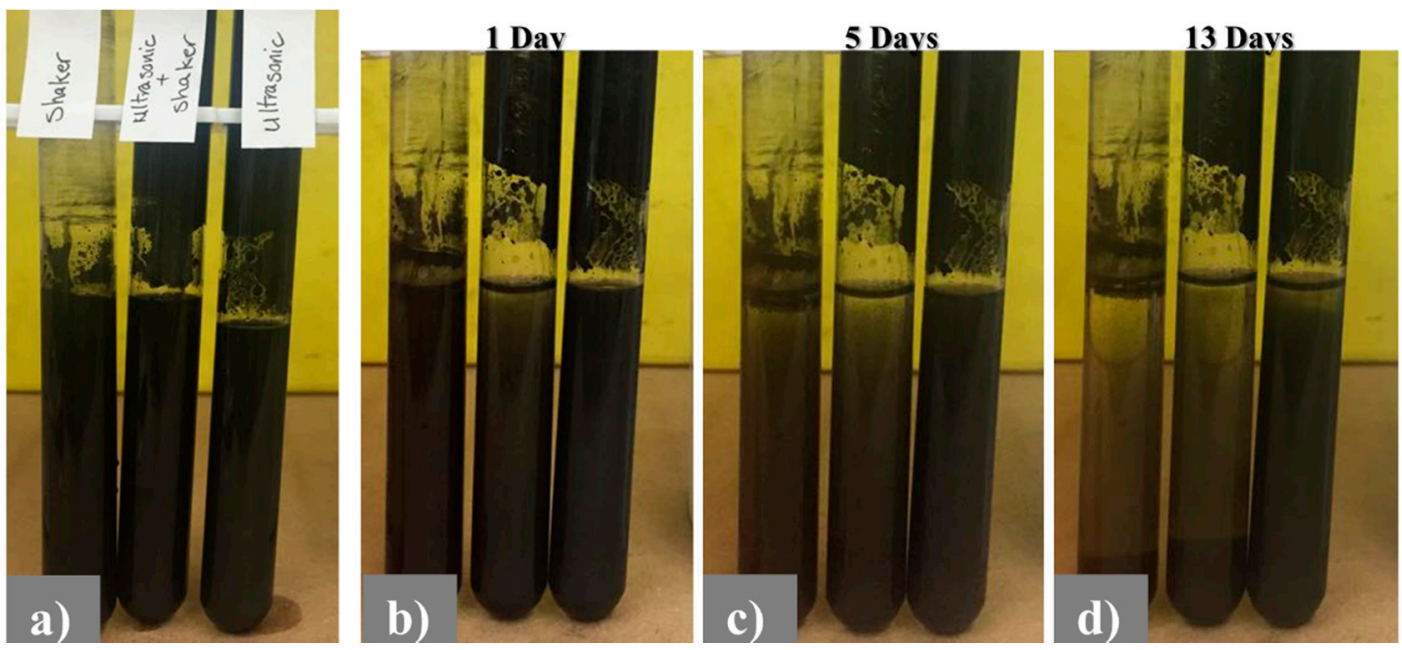

Figure 1. Compression of stability of mixing methods in several days: (a) after mixing, (b) 1 day, (c) 5 day and (d) 13 days.

\subsection{Tribological Performance}

The COF results showed that adding solid lubricant improved COF as expected, as shown in Figure 2. The high value of COF for neat canola oil resulted from a large real contact area of the mating surface. This improvement in reduction of COF of lubricants in presence of solid lubricants (graphite and graphene) can be attributed to the layered structure of graphite and graphene due to their lubrication nature. In addition, during contact between two solid surfaces, ultrathin graphene entrapped between mating surfaces can fill up the micro- and nano-gaps of the rubbing surfaces. Consequently, a tribolayer will form on the worn surfaces and can reduce the direct contact of the two surfaces, resulting in the improved COF. The nanoparticles usually form a thin transfer layer on the surface of the tribocontacts that is able to support partial hydrodynamic forces, reducing surface-to-surface contact of the asperities resulting in less friction, wear and surface damage. It can be concluded that adding graphene particles into oil is more effective than graphite particles for improving 
COF. This matches previous results as shown by Marchetto [33] where graphene particles have a lower $\mathrm{COF}$ than graphite particles due to the ultimate mechanical strength [21]. When comparing graphite and graphene, it should be considered that graphene is thin layers (i.e., platelets) and the graphite is often significantly larger and can be considered similar to buckyballs. In addition, the geometry of the graphene is planar and therefore, the graphene can more easily penetrate into the interface because it is nano-sized and has two important reasons for reducing friction: (1) Forming a nanobearing between moving surfaces and (2) Forming tribofilm in concave of the rubbing face which can decrease shearing stress, and therefore give a low friction coefficient. Generally, the presence of solid lubricant additives in base oil has the ability to act as a mechanical reinforcing element during friction. Hence, it can improve the load carrying capacity of the lubricant. Figure 2 reveals that adding more graphite particles is not recommended and sometimes can have a negative effect on the COF. Therefore, using solid lubricant in liquid lubricants needs an "optimal concentration". The optimum values of the COF were obtained in the presence of $0.7 \mathrm{wt} \%$ graphene into oil. Particle additive concentrations below the optimum concentration resulted in insufficient load carrying capacity. On the contrary, when the particle additive concentration was above the optimum concentration, the excessive additive in the base oil decreased the load carrying capacity due to the formation of lumps in the interface which resulted in worse lubricating efficacy.
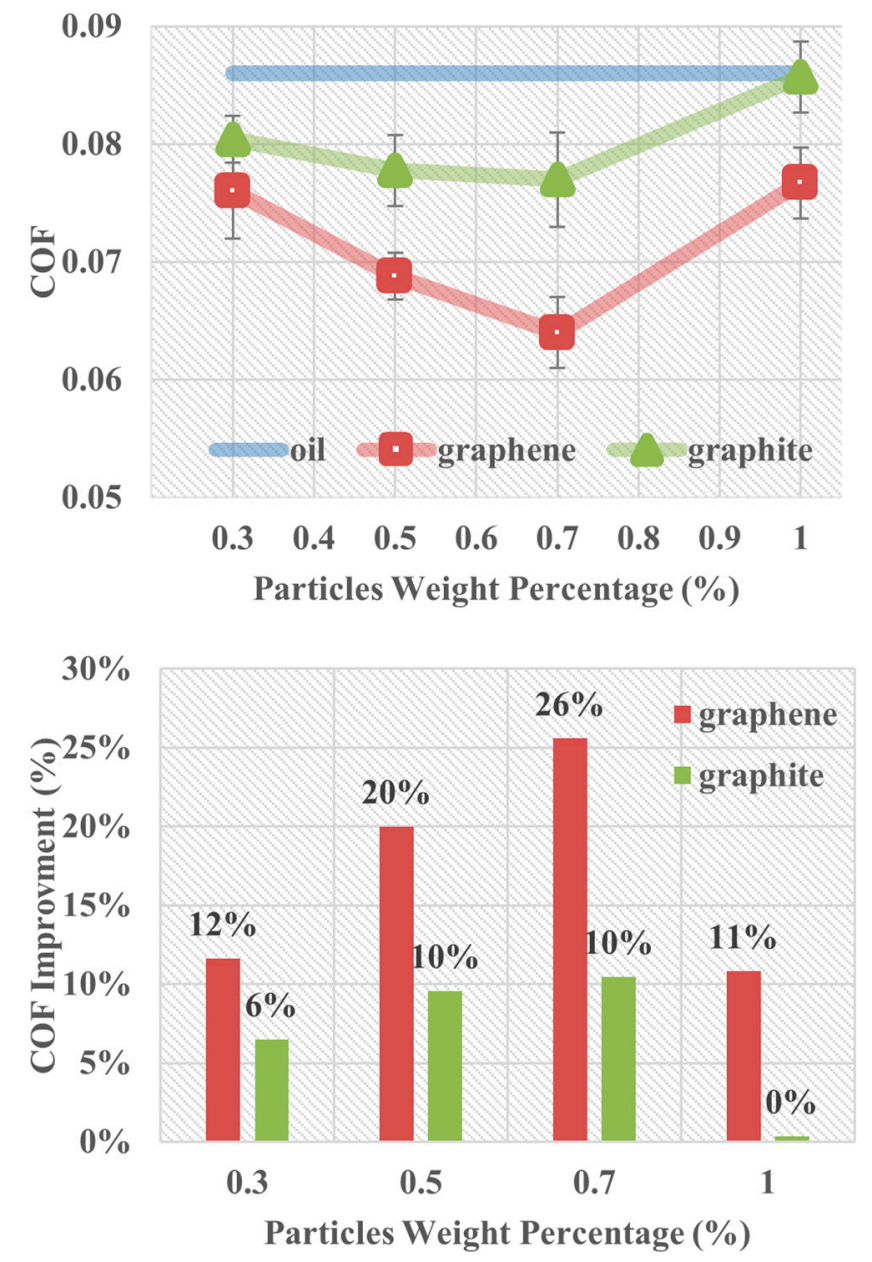

Figure 2. The variation of coefficient of friction (COF) and COF improvement in different weight percentage of graphite and graphene.

Surface characterization of samples showed some black spot on the contact surface for both samples in lubrication condition with adding graphite and graphene (Figure 3). These were graphite 
and graphene particles that are good evidence for reduced real contact area between pin and disk. Consequently, the reduction of the COF in presence of additives was attributed to this phenomenon.
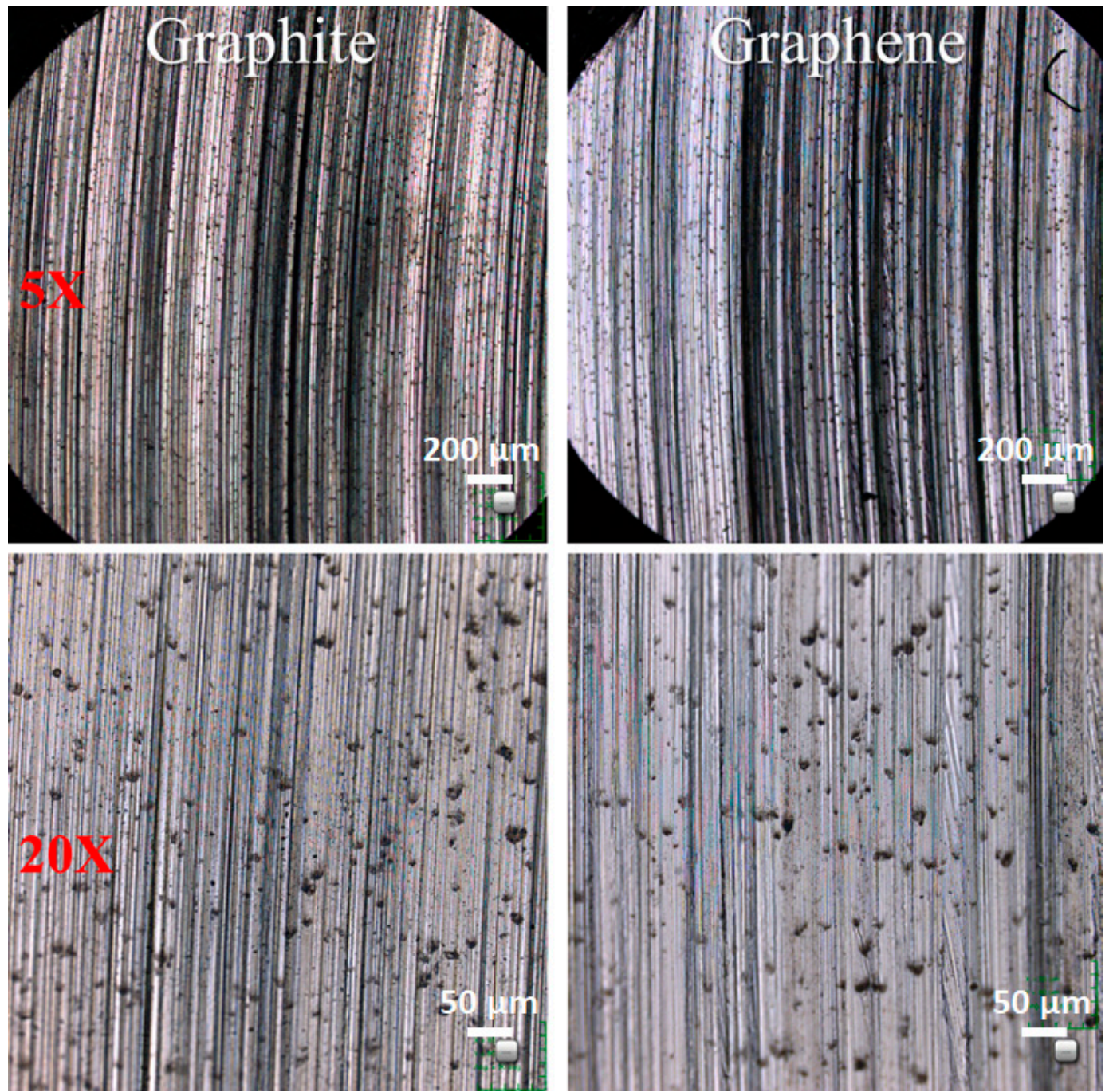

Figure 3. Microscopic image of the worn surface.

As expected, adding solid lubricant to oil can improve the wear rate of aluminum (Figure 4). Also, oil/graphite had a higher wear rate than oil/graphene because the graphite particles were bigger than the graphene and acted as third body abrasive particles. In addition, when the graphite was compared to graphene, graphite could not easily penetrate into the sliding surfaces, so graphite's effect to improve antiwear properties was lower than that of graphene. In other words, the graphene improves antiwear properties more than the flake graphite. Furthermore, the same trend for wear rate was observed as $0.7 \mathrm{wt} \%$ graphene showed a lower wear rate. Improvements at this optimum percentage of $0.7 \%$ was $83 \%$. 

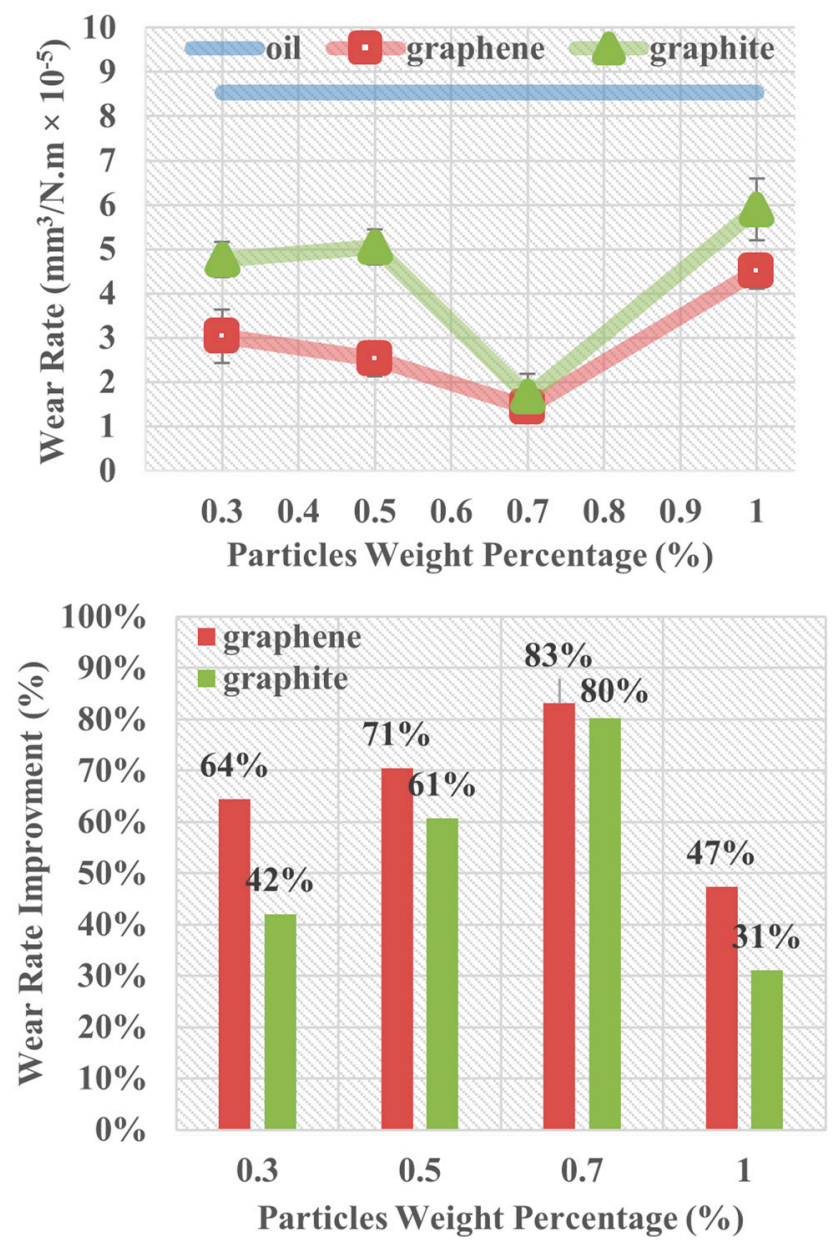

Figure 4. The variation of wear rate and wear rate improvement in different weight percentage of graphite and graphene.

\subsection{Surface Analysis}

The SEM images of the worn surface exhibited the distribution of graphene and graphite particles on the rubbing surface, as shown in Figure 5. The spots marked with red are graphite and graphene particles that formed a lubricant film. To confirm that these spots contain graphite or graphene, EDX was employed and the composition for one spot on the tribofilm and one spot on the surface were examined as shown in Figure 6. As observed, in the points with solid lubricant particles, 60 or 22 atomic percentage carbon existed while in another area of worn surfaces, there was no evidence of the presence of carbon. Hence, the graphite can exist in the tribo-interface by canola oil, implying that the solid lubricant formed physical deposition layers in several areas of the worn surface and decreased direct contact between mating surfaces. These results further indicate that graphene was better at decreasing the wear rate of the oil and showed better tribological properties. Figure 7 depicts the elemental mapping of carbon analysis for a sample surface tested with graphene. The map shows the concentration of carbon on the worn surface and indicates that traces of the element carbon existed on the surfaces in the presence of graphene into oil during the test, and that nanoparticles played a significant role in acting upon the tribological contacts. 

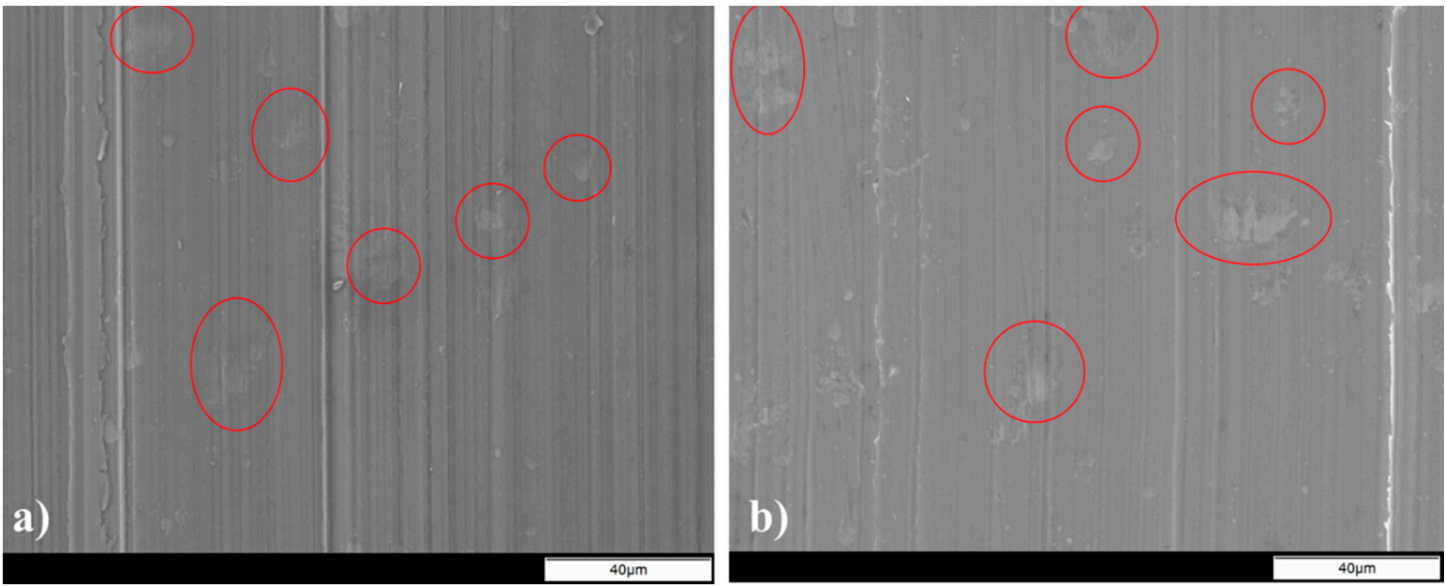

Figure 5. SEM image of the worn surface and presence of (a) graphene and (b) graphite on the worn surface.

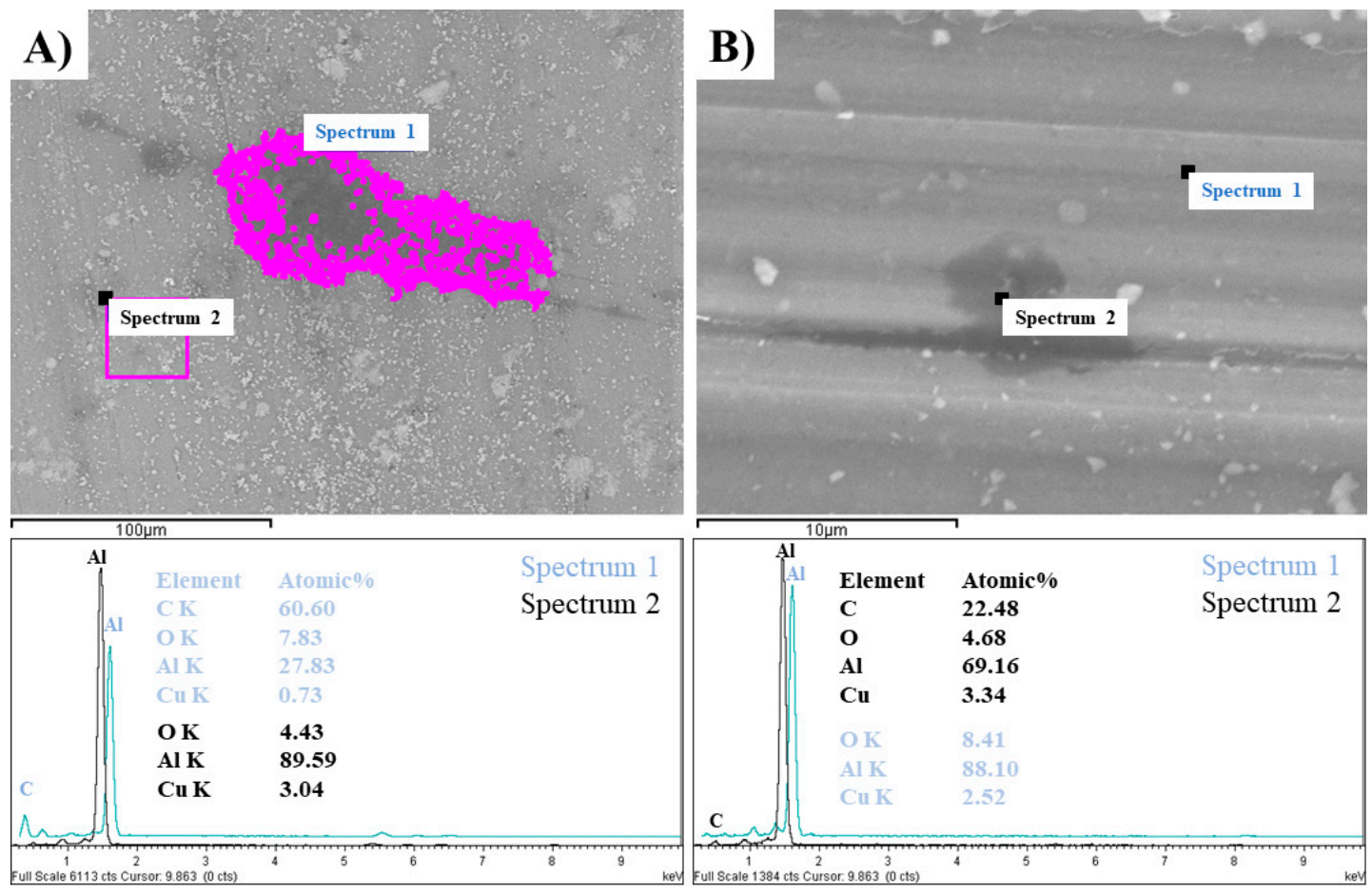

Figure 6. EDX of the worn surface in presence of lubricant additive of (A) graphene and (B) graphite. 


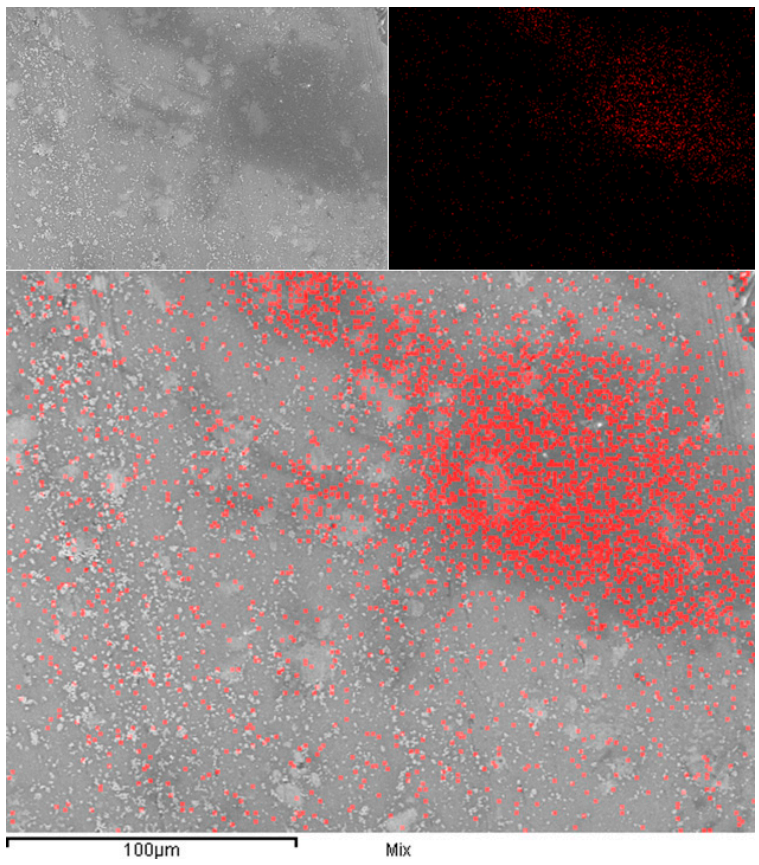

Figure 7. SEM image and elemental mapping for the surfaces tested with graphene as an oil additive.

Surface analysis showed that the worn surfaces in presence of graphene and graphite were smoother than neat oil, as shown in Figures 8 and 9, respectively. It was found that the worn surface lubricated only by canola oil was rougher with many thick and deep grooves, but the worn surfaces lubricated by oil with graphene and graphite was comparably smoother and the grooves were shallower. In addition, adding $0.7 \%$ graphene and graphite made smother surfaces, as observed in the figures. There was a correlation between wear rate and roughness after the test. Hence, where the wear rate was low, the surface roughness was low. Figure 10 reveals that the surface roughness showed the same trend as that of wear rate.

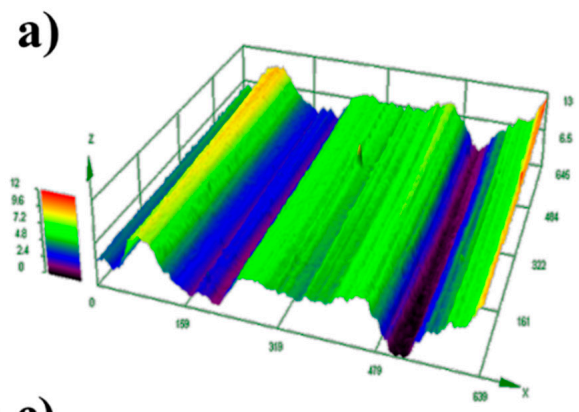

c)

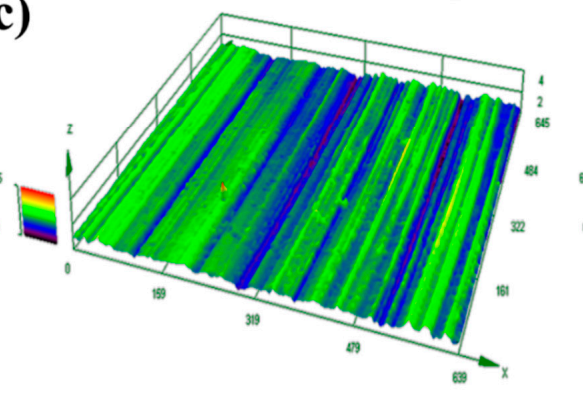

b)

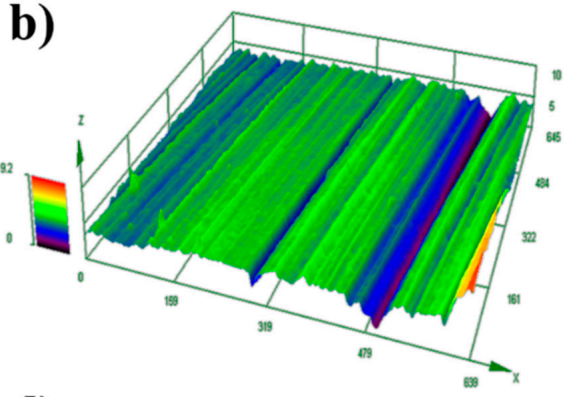

d)

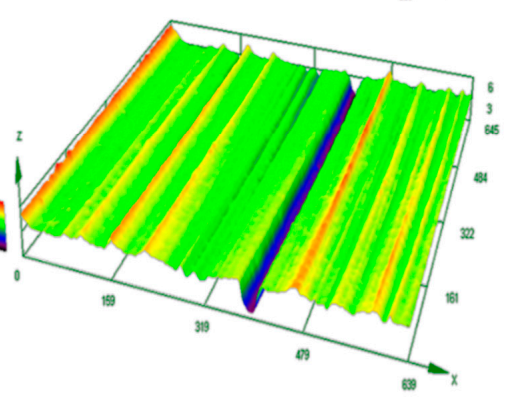

Figure 8. The 3D image of the worn surface for graphene oil additives for (a) neat oil, (b) $0.3 \mathrm{wt} \%$, (c) $0.7 \mathrm{wt} \%$, (d) $1 \mathrm{wt} \%$. 

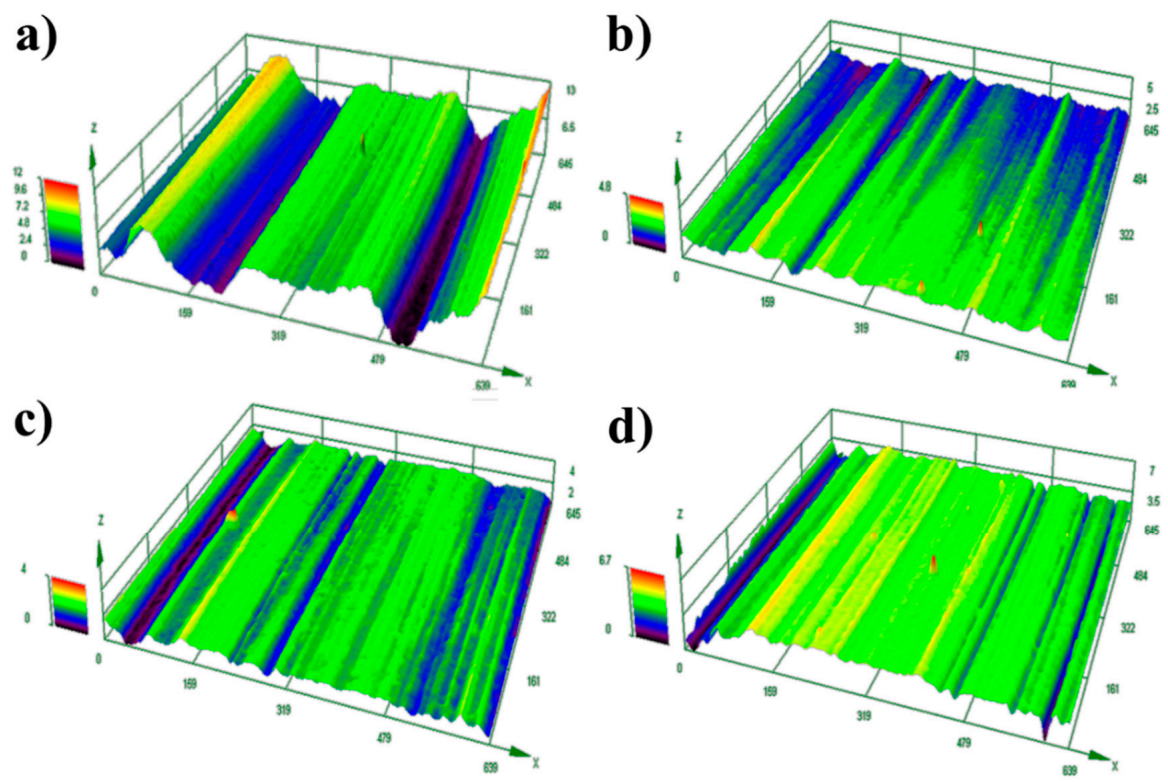

Figure 9. The 3D image of the worn surface for graphite oil additives for (a) neat oil, (b) $0.3 \mathrm{wt} \%$, (c) $0.7 \mathrm{wt} \%$, (d) $1 \mathrm{wt} \%$.
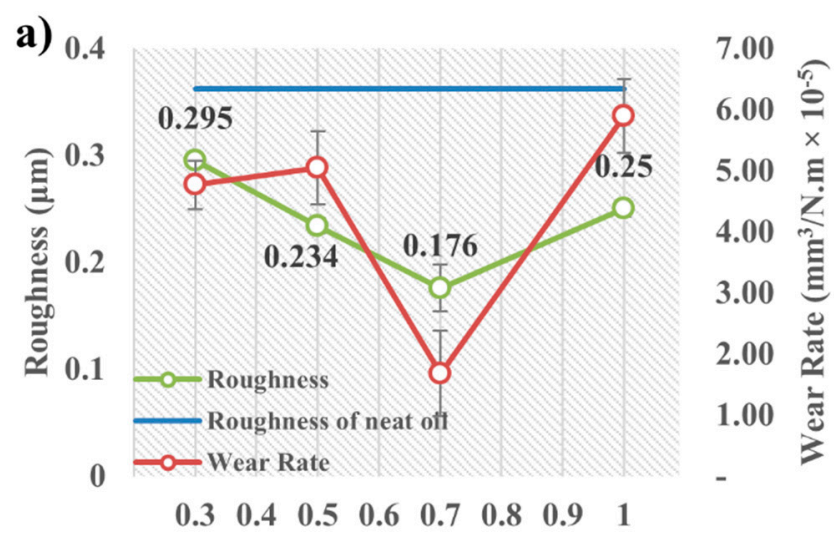

Graphite Weight Percentage (\%)

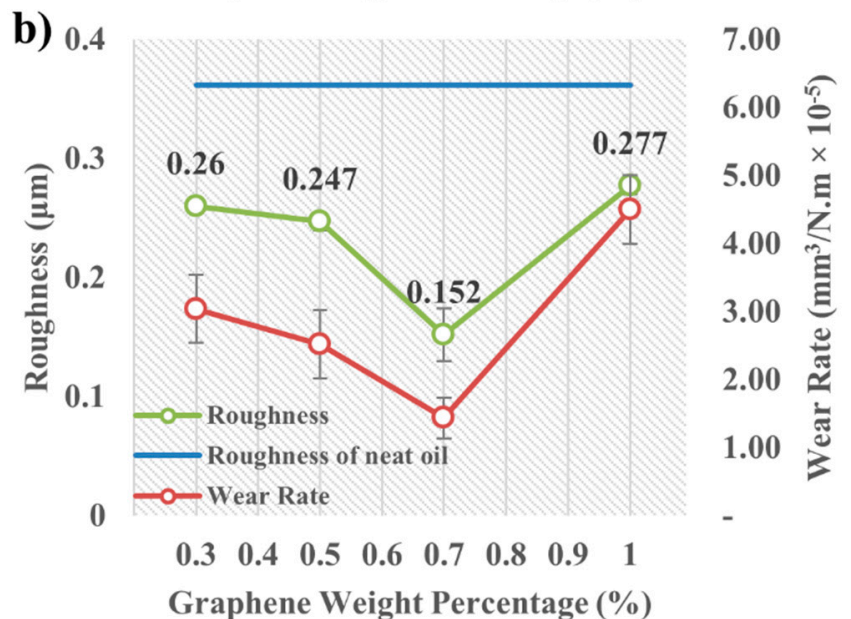

Figure 10. The variation of surface roughness of worn surfaces in different (a) graphite and (b) graphene weight percentages. 


\section{Conclusions}

This study suggests that both friction and wear can be dramatically improved in the presence of a solid lubricant (graphite and graphene) as an oil additive for canola oil. The geometry of the graphene and graphite is planar, and can easily slide between the surfaces in the oil. The current investigation was able to achieve the best results for optimum concentration of graphene and graphite in the base oil. Further, an increase in concentration results in aggregation and coagulation of graphene, increasing the wear and friction between surfaces. The worn surfaces exhibited several spots of graphite and graphene that reduce the real contact area and tends to lower COF and wear rate. The worn surfaces were smoother in the presence of graphite and graphene due to lower wear rate. Generally, graphene is more effective than graphite to improve tribological properties because it is in the nano range and can easily penetrate between sliding surfaces.

Author Contributions: Conceptualization, E.O., P.L.M. and P.K.R.; methodology, E.O.; validation, E.O., P.L.M. and P.K.R.; formal analysis, E.O.; investigation, E.O.; data curation, E.O.; writing-original draft preparation, E.O.; writing-review and editing, E.O., P.L.M. and P.K.R.; visualization, E.O.; supervision, P.L.M. and P.K.R.; project administration, P.K.R.

Funding: This research received no external funding.

Acknowledgments: We thank Asbury Carbons Company for providing solid lubricants, and Farhad Balali for their help.

Conflicts of Interest: The authors declare no conflict of interest.

\section{References}

1. Gao, J.; Luedtke, W.; Gourdon, D.; Ruths, M.; Israelachvili, J.; Landman, U. Frictional forces and Amontons' law: From the molecular to the macroscopic scale. J. Phys. Chem. B 2004, 108, 3410-3425. [CrossRef]

2. Zhou, J.; Wu, Z.; Zhang, Z.; Liu, W.; Xue, Q. Tribological behavior and lubricating mechanism of $\mathrm{Cu}$ nanoparticles in oil. Tribol. Lett. 2000, 8, 213-218. [CrossRef]

3. Greenberg, R.; Halperin, G.; Etsion, I.; Tenne, R. The effect of WS2 nanoparticles on friction reduction in various lubrication regimes. Tribol. Lett. 2004, 17, 179-186. [CrossRef]

4. Huang, H.; Tu, J.; Zou, T.; Zhang, L.; He, D. Friction and wear properties of IF-MoS 2 as additive in paraffin oil. Tribol. Lett. 2005, 20, 247-250. [CrossRef]

5. Tarasov, S.; Kolubaev, A.; Belyaev, S.; Lerner, M.; Tepper, F. Study of friction reduction by nanocopper additives to motor oil. Wear 2002, 252, 63-69. [CrossRef]

6. Xu, T.; Zhao, J.; Xu, K.; Xue, Q. Study on the tribological properties of ultradispersed diamond containing soot as an oil additive@. Tribol. Trans. 1997, 40,178-182. [CrossRef]

7. Liu, W.; Chen, S. An investigation of the tribological behaviour of surface-modified ZnS nanoparticles in liquid paraffin. Wear 2000, 238, 120-124. [CrossRef]

8. Chen, S.; Liu, W.; Yu, L. Preparation of DDP-coated PbS nanoparticles and investigation of the antiwear ability of the prepared nanoparticles as additive in liquid paraffin. Wear 1998, 218, 153-158. [CrossRef]

9. Xue, Q.; Liu, W.; Zhang, Z. Friction and wear properties of a surface-modified TiO 2 nanoparticle as an additive in liquid paraffin. Wear 1997, 213, 29-32. [CrossRef]

10. Wo, H.-Z.; Hu, K.-H.; Hu, X.-G. Tribological Properties of MoS 2 Nanoparticles as Additive in a Machine Oil. Tribology 2004, 24, 37-40.

11. Thakre, A.A.; Thakur, A.; Taylor, J. Study of behaviour of aluminium oxide nanoparticles suspended in SAE20W40 oil under extreme pressure lubrication. Ind. Lubr. Tribol. 2015, 67, 328-335. [CrossRef]

12. Jeng, Y.-R.; Huang, Y.-H.; Tsai, P.-C.; Hwang, G.-L. Tribological Performance of Oil-Based Lubricants with Carbon-Fe Nanocapsules Additive. Tribol. Trans. 2015, 58, 924-929. [CrossRef]

13. Nunn, N.; Mahbooba, Z.; Ivanov, M.; Ivanov, D.; Brenner, D.; Shenderova, O. Tribological properties of polyalphaolefin oil modified with nanocarbon additives. Diam. Relat. Mater. 2015, 54, 97-102. [CrossRef]

14. $\mathrm{Hu}, \mathrm{X}$. On the size effect of molybdenum disulfide particles on tribological performance. Ind. Lubr. Tribol. 2005, 57, 255-259. [CrossRef] 
15. Lee, C.-G.; Hwang, Y.-J.; Choi, Y.-M.; Lee, J.-K.; Choi, C.; Oh, J.-M. A study on the tribological characteristics of graphite nano lubricants. Int. J. Precis. Eng. Manuf. 2009, 10, 85-90. [CrossRef]

16. Lin, J.; Wang, L.; Chen, G. Modification of graphene platelets and their tribological properties as a lubricant additive. Tribol. Lett. 2011, 41, 209-215. [CrossRef]

17. Omrani, E.; Moghadam, A.D.; Menezes, P.L.; Rohatgi, P.K. Influences of graphite reinforcement on the tribological properties of self-lubricating aluminum matrix composites for green tribology, sustainability, and energy efficiency-A review. Int. J. Adv. Manuf. Technol. 2016, 83, 325-346. [CrossRef]

18. Moghadam, A.D.; Omrani, E.; Menezes, P.L.; Rohatgi, P.K. Mechanical and tribological properties of self-lubricating metal matrix nanocomposites reinforced by carbon nanotubes (CNTs) and graphene-A review. Compos. Part B Eng. 2015, 77, 402-420. [CrossRef]

19. Moghadam, A.D.; Schultz, B.F.; Ferguson, J.; Omrani, E.; Rohatgi, P.K.; Gupta, N. Functional metal matrix composites: Self-lubricating, self-healing, and nanocomposites-an outlook. JOM 2014, 66, 872-881. [CrossRef]

20. Huang, H.; Tu, J.; Gan, L.; Li, C. An investigation on tribological properties of graphite nanosheets as oil additive. Wear 2006, 261, 140-144. [CrossRef]

21. Eswaraiah, V.; Sankaranarayanan, V.; Ramaprabhu, S. Graphene-based engine oil nanofluids for tribological applications. ACS Appl. Mater. Interfaces 2011, 3, 4221-4227. [CrossRef] [PubMed]

22. Ames, W.; Alpas, A.T. Wear mechanisms in hybrid composites of graphite-20 Pct SiC in A356 aluminum alloy (Al-7 Pct Si-0.3 Pct Mg). Metall. Mater. Trans. A 1995, 26, 85-98. [CrossRef]

23. Riahi, A.R.; Alpas, A.T. The role of tribo-layers on the sliding wear behavior of graphite aluminum matrix composites. Wear 2001, 251, 1396-1407. [CrossRef]

24. Guo, M.L.T.; Tsao, C.Y.A. Tribological behavior of aluminum/SiC/nickel-coated graphite hybrid composites. Mater. Sci. Eng. 2002, 333A, 134-145.

25. Lakshminarayanan, P.A.; Nayak, N.S. Tribological tests to simulate wear on piston rings. In Critical Component Wear in Heavy Duty Engines; John Wiley \& Sons Ltd.: Singapore, 2011; pp. 167-195.

26. Akhlaghi, F.; Zare-Bidaki, A. Influence of graphite content on the dry sliding and oil impregnated sliding wear behavior of Al 2024-graphite composites produced by in situ powder metallurgy method. Wear 2009, 266, 37-45. [CrossRef]

27. Omrani1, E.; Moghadam, A.D.; Algazzar, M.; Moghadam, A.D.; Algazzar, M.; Menezes, P.L.; Rohatgi, P.K. Effect of graphite particles on improving tribological properties Al-16Si-5Ni-5Graphite self-lubricating composite under fully flooded and starved lubrication conditions for transportation applications. Int. J. Adv. Manuf. Technol. 2016, 87, 929-939. [CrossRef]

28. Aranganathan, N.; Bijwe, J. Comparative performance evaluation of NAO friction materials containing natural graphite and thermo-graphite. Wear 2016, 358-359, 17-22. [CrossRef]

29. Novoselov, K.S.; Geim, A.K.; Morozov, S.V.; Geim, A.K.; Morozov, S.V.; Jiang, D.; Zhang, Y.; Dubonos, S.V.; Grigorieva, I.V.; Firsov, A.A. Electric field effect in atomically thin carbon films. Science 2004, 306, 666-669. [CrossRef] [PubMed]

30. Lee, C.G.; Wei, X.D.; Li, Q.Y.; Wei, X.; Li, Q.; Carpick, R.; Kysar, J.W.; Hone, J. Elastic and frictional properties of graphene. Phys. Status Solidi B 2009, 246, 2562-2567. [CrossRef]

31. Shin, Y.J.; Stromberg, R.; Nay, R.; Stromberg, R.; Nay, R.; Huang, H.; Wee, A.T.S.; Yang, H.; Bhatia, C.S. Frictional characteristics of exfoliated and epitaxial graphene. Carbon 2011, 49, 4059-4073. [CrossRef]

32. Sandoz-Rosado, E.J.; Tertuliano, O.A.; Terrell, E.J. An atomistic study of the abrasive wear and failure of graphene sheets when used as a solid lubricant and a comparison to diamond-like-carbon coatings. Carbon 2012, 50, 4078-4084. [CrossRef]

33. Marchetto, D.; Held, C.; Hausen, F. Friction and wear on single-layer epitaxial graphene in multi-asperity contacts. Tribol. Lett. 2012, 48, 77-82. [CrossRef]

34. Berman, D.; Erdemir, A.; Sumant, A.V. Few layer graphene to reduce wear and friction on sliding steel surfaces. Carbon 2013, 54, 454-459. [CrossRef]

35. Arwin, G.Z.; Rashmi, G.W. Tribological Evaluation of nano graphene Platelets as an additive to biolubricant base fluid. In EURECA 2013; Taylor's University: Subang Jaya, Malaysia, 2013.

36. Zhang, W.; Zhou, M.; Zhu, H.W. Tribological properties of oleic acid-modified graphene as lubricant oil additives. J. Phys. D 2011, 44, 205303. [CrossRef]

37. Choudhary, S.; Mungse, H.P.; Khatri, O.P. Dispersion of alkylated graphene in organic solvents and its potential for lubrication applications. J. Mater. Chem. 2012, 22, 21032-21039. [CrossRef] 
38. Reeves, C.J.; Menezes, P.L.; Lovell, M.R.; Jen, T.-C. The influence of surface roughness and particulate size on the tribological performance of bio-based multi-functional hybrid lubricants. Tribol. Int. 2015, 88, 40-55. [CrossRef]

39. Reeves, C.J.; Menezes, P.L.; Jen, T.-C.; Lovell, M.R. The influence of fatty acids on tribological and thermal properties of natural oils as sustainable biolubricants. Tribol. Int. 2015, 90, 123-134. [CrossRef]

40. Mistry, K.K.; Pol, V.G.; Thackeray, M.M.; Wen, J.; Miller, D.J.; Erdemir, A. Synthesis and tribology of micro-carbon sphere additives for enhanced lubrication. Tribol. Trans. 2015, 58, 474-480. [CrossRef] 